\title{
Modelling the effects of osmotic stress on tomato fruit development
}

\author{
B.A.E. Van de Wal ${ }^{1, a}$, H.A.L. Van de Put ${ }^{1}$, J. Hanssens ${ }^{1}$ and K. Steppe ${ }^{1}$ \\ ${ }^{1}$ Laboratory of Plant Ecology, Faculty of Bioscience Engineering, Ghent University, Ghent, Belgium
}

\section{Abstract}

Whereas most high-tech tomato greenhouses focus primarily on high production yields, consumers prefer a higher quality product. Dry matter content is one of the key factors determining fruit quality, and is known to be substantially influenced by altering the salinity of the nutrient solution. While this imposed osmotic stress can improve fruit quality, this often goes hand in hand with a decrease in production due to less water accumulation in the fruit. A more thorough insight in the underlying mechanisms might contribute to a better understanding and eventually steering of this delicate balance. To achieve this deeper knowledge, we combined intensive monitoring of plant and fruit physiological variables with a model-based approach. An experiment on tomato (Solanum lycopersicum L. 'Dirk') was set up in a greenhouse, where two different water treatments were imposed by altering the salinity (Electric Conductivity, EC) of the substrate. Besides plant variables such as sap flow, stem diameter variation and stem water potential, fruit growth and quality parameters were measured as well. These data were then used in a recently developed virtual tomato plant and fruit model, which is capable of modelling both plant and fruit growth as well as fruit quality (sugars and acids) and xylem and phloem contribution to fruit growth, but which has not been tested under salt stressed conditions. Results did not only show that the model can be used to predict fruit growth during salt stress conditions, but also which model parameters and related plant traits are affected most. This is an important step towards a better understanding of the underlying mechanisms controlling fruit development under osmotic stress.

Keywords: water deficit, mechanistic modelling, LVDT, fruit growth, plant water status, carbon relations, water relations

\section{INTRODUCTION}

High production is the main concern of most tomato growers in high-tech greenhouses, which are the standard in Northern Europe. As consumers become more demanding, fruit quality has gained in importance over the past few years. This quality is not only determined by the fruit's appearance, being color, size and shape, but also by texture, firmness, aroma and taste (Dorais et al., 2001a; Guichard et al., 2001). Since soluble sugars represent approximately 50\% of the total dry matter (Davies and Hobson, 1981), it is evident that they are strongly related to fruit quality.

Increased salinity of the nutrient solution is an important factor influencing the quality (dry matter content) and production (fresh weight) of tomato fruits by affecting water and dry matter accumulation. Generally, dry matter content increases with salinity, while the water influx, and thus the fresh weight, decreases (Ho et al., 1987; Cuartero and Fernández-Muñoz, 1999; Plaut et al., 2004). Consequently, an increase in quality is mostly accompanied by a decrease in production. Moreover, both production and quality are also influenced by the genotype (Turhan and Seniz, 2009; Caliman et al., 2010; Beckles, 2012)

a E-mail: bart.vandewal@UGent.be 
and an array of environmental factors. For example, high light intensities increase the dry matter content by increasing the photosynthesis rate (Dorais et al., 2001b) and decreasing the xylem contribution to water driven fruit expansion and fresh weight growth (Hanssens et al., 2015). Another important environmental factor is vapour pressure deficit (VPD), since a higher VPD increases fruit transpiration. Furthermore, it leads to a more negative total water potential in the stem, resulting in a smaller water potential gradient between stem and fruit, and thus a decreased xylem influx into the fruit (Leonardi et al., 2000; Guichard et al., 2005, Hanssens et al., 2015).

While the effects of environmental conditions and water deficit on fruit quality have been studied repeatedly, underlying mechanisms are not yet fully clarified. Combination of intensive plant and fruit measurements with a model-based approach can help broaden the knowledge on this matter. Therefore, in this study, an existing mechanistic model was used to examine the effects of osmotic stress on tomato fruit development. The model integrates plant water and carbon status, and fruit water and carbon accumulation (Hanssens, 2015; Hanssens et al., 2015) but has not been tested under high salinity nor water deficit conditions. Therefore, we applied the model on a control group as well as on plants subjected to a salinity treatment, in order to deepen our physiological understanding of the effects of osmotic stress on fruit quality and production.

\section{MATERIALS AND METHODS}

\section{Experimental setup}

Tomato plants (Solanum lycopersicum L. 'Dirk') were sown in rockwool blocks (Grodan Delta, Grodan, Roermond, the Netherlands) on 3 July 2014 and were transferred to a $60 \mathrm{~m}^{2}$ glasshouse compartment of the Institute for Agricultural and Fisheries Research (ILVO) in Melle, Belgium on 16 July 2014, where the blocks were transplanted onto rockwool slabs (Grodan Vital, Grodan, Roermond, The Netherlands) on 2 September 2014. The experiment ended on 16 December 2014. Anthesis was checked daily in order to allow accurate estimation of fruit age and trusses were all pruned to five fruits per truss. The plants were irrigated every 90 minutes between $9.30 \mathrm{~h}$ and $20.00 \mathrm{~h}$, or when radiation sum exceeded $200 \mathrm{~J} \mathrm{~cm}^{-2}$, by a trickle irrigation system.

Two treatments were imposed on a gutter of nine plants each: a control group (henceforth referred to as ' $\mathrm{C}$ ') and a salt stress group (' $\mathrm{S}$ '). Both groups received ample irrigation (i.e. $30-50 \%$ drain), but the EC levels were $2.7 \mathrm{mS} \mathrm{cm}^{-1}$ and $6 \mathrm{mS} \mathrm{cm}^{-1}$ for C and S, respectively. The $\mathrm{EC}$ for $\mathrm{S}$ was increased by adding a $4: 1 \mathrm{~mol} / \mathrm{mol} \mathrm{NaCl} / \mathrm{CaCl}_{2}$ solution to the nutrient solution. To avoid border effects, edge plants were not used in the experiment and tomato plants were also placed in the gutters adjacent to the experiment.

\section{Microclimatic measurements}

The microclimate in the glasshouse compartment was continuously monitored. Photosynthetic active radiation (PAR) was measured with a PAR sensor (JYP1000, SDEC, Reignac-sur-Indre, France). Relative humidity $(\mathrm{RH})$ and air temperature $\left(\mathrm{T}_{\mathrm{a}}\right)$ were measured with a RH sensor (EE08, E+E Elektronik, Engerwitzdorf, Austria) and a copper-constantan thermocouple (Type T, Omega, Amstelveen, the Netherlands), respectively, both installed in a ventilated radiation shield.

\section{Plant measurements}

Sap flow (SF) and stem diameter variations $\left(D_{\text {stem }}\right)$ were continuously monitored with a heat balance sap flow sensor (SGA10-WS of SGA13-WS, Dynamax Inc., Houston, TX, US) and a linear variable displacement transducer (LVDT, Solartron, Bognor Regis, UK), respectively. In addition, daily patterns of the total stem water potential in the xylem $\left(\Psi_{\text {stem }}\right)$ 
was measured manually every week on three plants per treatment using a Scholander pressure chamber (Model 1000, PMS instruments, Albany, OR, USA).

\section{Fruit measurements}

For the analysis of the hexose sugars (fructose and glucose), the third tomato of each ripe truss was immediately frozen in liquid nitrogen at harvest, and stored at $-80^{\circ} \mathrm{C}$. The sugars were extracted from the ground fruit samples with $100 \%$ ethanol at $70^{\circ} \mathrm{C}$ for $10 \mathrm{~min}$, followed by $3 \mathrm{~h}$ at $45^{\circ} \mathrm{C}$, centrifugation at $5000 \mathrm{~g}$, and $8^{\circ} \mathrm{C}$ for $10 \mathrm{~min}$. Chromatographic separation and detection was achieved using a Prevail Carbohydrate column $(250 \times 4.6 \mathrm{~mm}$, $5 \mu \mathrm{m}$ ) (Grace Alltech, Deerfield Illinois, USA) and an Agilent 1100 High Performance Liquid Chromatography (HPLC) system, coupled to an Alltech 3300 electrochemical light scattering detector (Grace Alltech, Deerfield, Illinois, USA).

Fruit diameter growth $\left(\mathrm{D}_{\mathrm{fr}}\right)$ was monitored twice a week using a calliper. In addition, the osmotic potential of the tomato fruits $\left(\Psi_{\pi}\right)$ was measured in function of fruit age for both treatments with a thermocouple psychrometer, consisting of a chamber (C-52, Wescor, Logan, UT, US), a switch box (PS-10, Wescor, Logan, UT, US), and a dewpoint microvoltmeter (HR-33T, Wescor, Logan, UT, US).

\section{Model calibration and simulation}

The model used in this study is a combination of the tomato fruit model of Liu et al. (2007) and the tomato plant model of De Swaef and Steppe (2010), the latter being based on the original plant model of Steppe et al. (2006). Measured SF, $\mathrm{T}_{\mathrm{a}}$ and RH served as input variables, whereas plant measurements $D_{\text {stem }}, \Psi_{\text {stem, }}$ and fruit measurements $D_{\mathrm{fr}}, \Psi_{\pi}$, fructose and glucose content were used to calibrate the model. For a detailed description of the model, we refer to Hanssens et al. (2015) and Hanssens (2015). Model simulations were run for two plants of each treatment.

Model calibration and simulation were performed with PhytoSim (Phyto-IT BVBA, Mariakerke, Belgium). Model calibration was done using the simplex method (Nelder and Mead, 1965) to minimise the weighted sum of the squared errors, and was carried out for each plant individually. For simulations, a fourth-order Runge-Kutta numerical integrator with a fixed step size of $0.01 \mathrm{~h}$ was used.

\section{RESULTS AND DISCUSSION}

\section{Fruit growth}

Fruit growth was significantly reduced in the salt treatment, resulting in a fruit diameter at harvest that was $32 \%$ lower than in C (Fig. 1). The model was able to simulate this fruit growth well, both for C and S. The decreased fruit growth in $\mathrm{S}$ was reflected in the calibrated model parameter values. While an overview of all parameters in the model is beyond the scope of this paper, we highlight the two parameters that were influenced the most, being $R_{x}$ and a (Fig. 2). $R_{x}$ represents the hydraulic resistance in the xylem compartment, and is known to increase substantially under water deficit (Baert et al., 2015). $\mathrm{R}_{\mathrm{x}}$ was $89 \%$ higher in $\mathrm{S}$ than in C. Parameter ' $\mathrm{a}$ ', which is a dimensionless proportionality constant related to the exchange surface between the vascular network and the fruit, was reduced by $46 \%$ in $S$ compared to $C$. It has indeed been shown that the diameter of the xylem vessels can be smaller both under water deficit (Kulkarni and Phalke, 2009) and salt stress conditions (Belda et al., 1996). However, parameter 'a' is also linked with the hydraulic conductivity in the peduncle. This hydraulic conductivity has been shown to decrease as well under water deficit conditions, possibly due to cavitation as a result of decreased water potential in the xylem (Van Ieperen et al., 2003; Kageyama et al., 2009). The decrease in 'a' can hence be possibly attributed to a combination of these two effects. 
Although responses to salinity and water deficit are known to be slightly different (Plaut et al. 2004), the affected parameters suggest that similar mechanisms are involved, at least regarding the water transport towards the fruit.

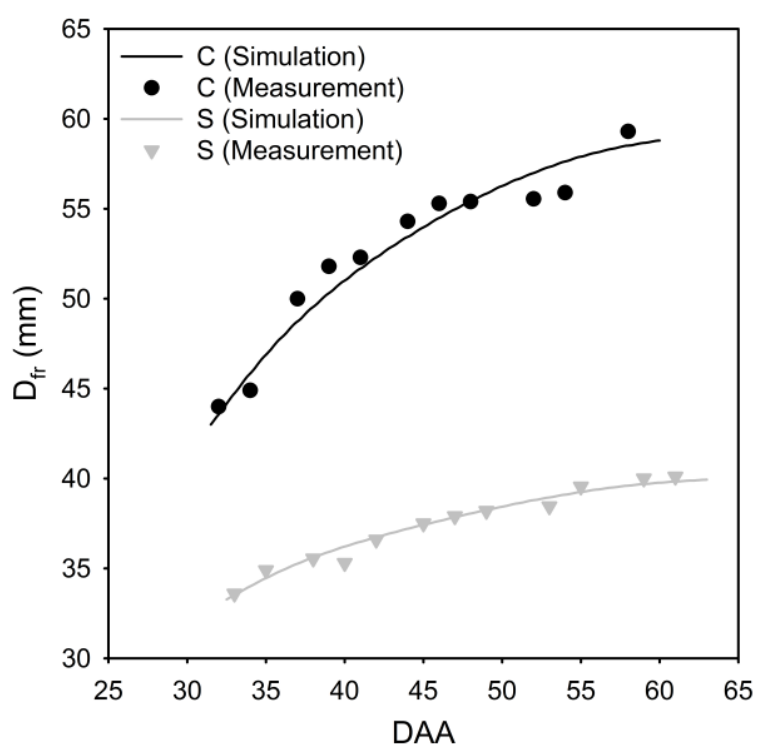

Fig. 1. Measured and simulated fruit diameter $\left(\mathrm{D}_{\mathrm{fr}}\right)$ as a function of fruit age (Days After Anthesis, DAA) for one plant of the control treatment (C, black line and circles) and one plant of the salt stress treatment ( $\mathrm{S}$, grey line and triangles). Measurements and simulations started on 5 November.

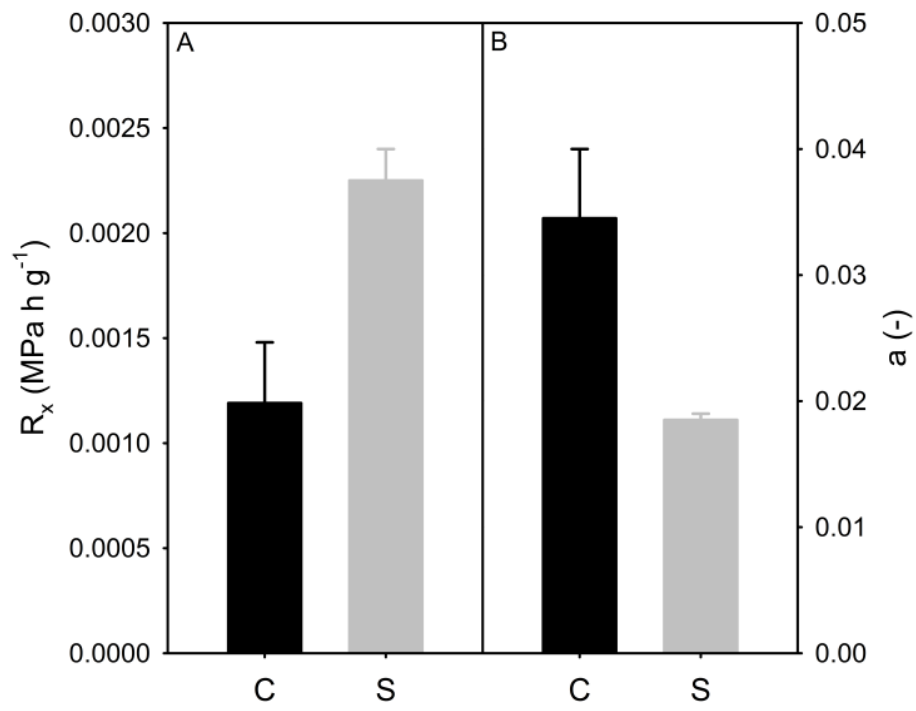

Fig. 2. Mean value $( \pm S E, n=2)$ of the estimated model parameters $R_{x}$ (hydraulic resistance of the xylem compartment in the stem, A) and 'a' (a proportionality constant related to the exchange surface between the vascular network and the fruit, $\mathrm{B}$ ) for the control treatment $(\mathrm{C}$, black bars) and the salt treatment $(\mathrm{S}$, grey bars). 


\section{Fruit quality}

While fruit growth was impeded by salt stress (Fig. 1), fruit sugar content was significantly higher in S compared to C (Fig. 3). Fructose and glucose concentrations were $128 \%$ and $132 \%$ higher, respectively. Since no sugar measurements during fruit development were performed, model simulation of glucose and fructose levels throughout the fruit development are not shown here. This increased sugar content is a direct evidence of improved organoleptic quality, since higher sugar content enhances perception of flavours associated with ripe, tropical, and aromatic tomatoes (Baldwin et al., 2008).

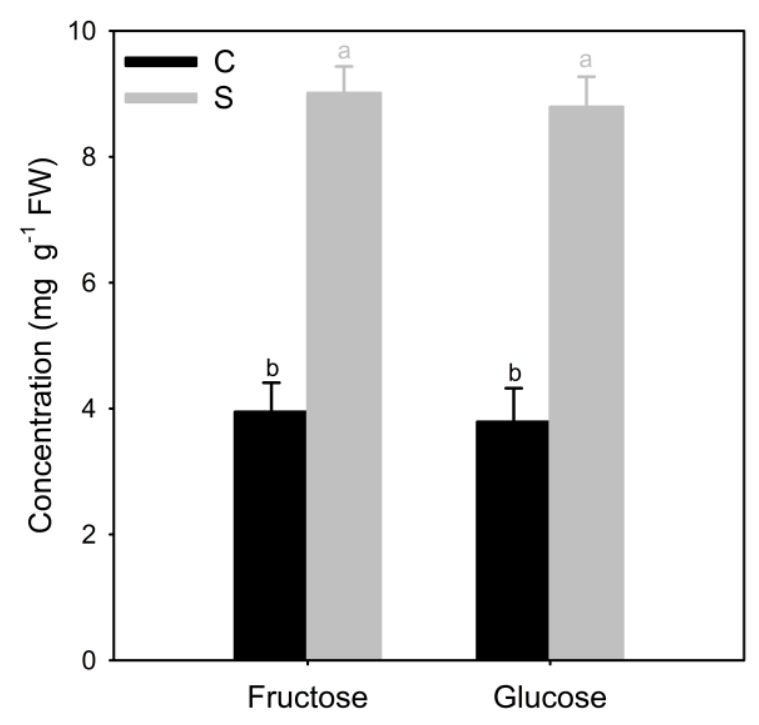

Fig. 3. Mean concentrations at harvest $( \pm S E, n=13)$ of the hexose sugars fructose and glucose for the control treatment $(\mathrm{C}$, black bars) and the salt treatment $(\mathrm{S}$, grey bars). Significant differences ( $t$-test, $\mathrm{P}<0.001$ ) across bars are denoted by different letters.

\section{CONCLUSIONS}

Fruit development was clearly affected by the imposed salt stress. This was reflected in increased sugar concentrations as well as in diminished fruit growth. While these effects are in accordance with literature, our modelling approach is a first step towards a better prediction of this impeded fruit growth under increased salinity and showed that the hydraulic resistance in the stem xylem and the hydraulic conductivity in the pedicel were the factors that were affected most. Further optimisation of the model can provide even more insights in plant functioning, and could eventually be used to optimise the balance between fruit growth and sugar concentration in commercial practice.

\section{ACKNOWLEDGEMENTS}

The authors thank the Agency for Innovation by Science and Technology in Flanders (IWT) for the PhD funding granted to BAEVdW and for the research project granted to KS (IWT 140961), which supports the PhD funding of HVdP. The authors are also indebted to Philip Deman, Geert Favyts and Erik Moerman for the technical support, and to Veerle De Schepper, Jesse Seynhaeve and Anne-Sofie Vandenbroucke for their assistance during the experiment. 


\section{Literature cited}

Baert, A., De Schepper, V., and Steppe, K. (2015). Variable hydraulic resistances and their impact on drought response modelling. Tree Physiol. 35, 439-449

Baldwin, E.A., Goodner, K., and Plotto, A. (2008). Interaction of volatiles, sugars, and acids on perception of tomato aroma and flavor descriptors. J. Food. Sci. 73, S294-S307

Beckles, D.M. (2012). Factors affecting the postharvest soluble solids and sugar content of tomato (Solanum lycopersicum L.) fruit. Postharvest Biol. Tec. 63, 129-140

Belda, R.M., Fenlon, J.S., and Ho, L.C. (1996). Salinity effects on the xylem vessels in tomato fruit among cultivars with different susceptibilities to blossom-end rot. J. Hort. Sci. 71, 173-179

Caliman, F.R.B., Da Silva, D.J.H., Stringheta, P.C., Fontes, P.C.R., Moreira, G.R., and Mantovani, E.C. (2010). Quality of tomatoes grown under a protected environment and field conditions. Idesia (Chile) 28, 75-82.

Cuartero, J., and Fernández-Muñoz, R. (1999). Tomato and salinity. Sci. Hortic. 78, 83-125

Davies, J., and Hobson, G. (1981). The constituents of tomato fruit - the influence of environment, nutrition and genotype. CRC Crit. Rev. Fruit Sci. Nutr. 15, 205-280.

De Swaef, T., and Steppe, K. (2010). Linking stem diameter variations to sap flow, turgor and water potential in tomato. Funct. Plant Biol. 37, 429-438.

Dorais, M., Papadopoulos, A.P., and Gosselin, A. (2001a). Greenhouse tomato fruit quality. In: Horicultural Reviews, Vol. 26., John Wiley \& Sons, Oxford. p.239-319.

Dorais, M., Papadopoulos, A.P., and Gosselin, A., (2001b). Influence of electric conductivity management on greenhouse tomato yield and fruit quality. Agronomie 21, 367-383.

Guichard, S., Bertin, N., Leonardi, G., and Gary, C. (2001). Tomato fruit quality in relation to water and carbon fluxes. Agronomie-Sciences des Productions Vegetales et de l'Environnement 21, 385-392.

Guichard, S., Gary, C., Leonardi, C., and Bertin, N. (2005). Analysis of growth and water relations of tomato fruits in relation to air vapor pressure deficit and plant fruit load. J. Plant Growth Regul. 24, 201-213.

Hanssens, J. (2015). Decision support for tomato growers based on plant responses, modelling and greenhouse energy consumption. Phd thesis, Ghent University, Belgium.

Hanssens, J., De Swaef, T., and Steppe, K. (2015). High light decreases xylem contribution to fruit growth in tomato. Plant Cell Environ. 38, 487-498.

Ho, L.C., Grange, R.I., and Picken, A.J. (1987). An analysis of the accumulation of water and dry matter in tomato fruit. Plant Cell Environ. 10, 157-162.

Kageyama, K., Inoue, Y., and Kato, H. (2009). Estimation for embolism risk of tomato using acoustic emission response to increased drought stress. Environ. Contr. Biol., 47(3), 127-136.

Kulkarni, M., and Phalke, S. (2009). Evaluating variability of root system and its constitutive traits in hot pepper (Capsicum annum L.) under water stress. Sci. Hortic. 120, 159-166

Leonardi, C., Guichard, S., and Bertin, N. (2000). High vapour pressure deficit influences growth, transpiration and quality of tomato fruit. Sci. Hortic. 84, 285-296.

Liu, H.F., Génard, M., Guichard, S., and Bertin, N. (2007). Model-assisted analysis of tomato fruit growth in relation to carbon and water fluxes. J. Exp. Bot. 58, 3567-3580

Nelder, J.A., and Mead, R. (1965), A simplex method for function minimization. Comput. J. 7, 308-313.

Plaut, Z., Grava, A., Yehezkel, C., and Matan, E. (2004). How do salinity and water stress affect transport of water, assimilates and ions to tomato fruits? Physiol. Plant. 122, 429-442.

Steppe, K., De Pauw, D.J.W., Lemeur, R., and Vanrolleghem, P.A. (2006). A mathematical model linking tree sap flow dynamics to daily stem diameter fluctuations and radial stem growth. Tree Physiol. 26,257-273.

Turhan, A., and Seniz, V. (2009) Estimation of certain chemical constituents of fruits of selected tomato genotypes grown in Turkey. Afr. J. Agric. Res. 4, 1086-1092.

Van Ieperen, W., Volkov, V. S., and Van Meeteren, U. (2003). Distribution of xylem hydraulic resistance in fruiting truss of tomato influenced by water stress. J. Exp. Bot., 54, 317-324. 